\title{
Investigation on Photoluminescence Behaviour of 2, 3-Diphenylquinoxalin-6-Vinyl Benzaldehyde
}

\author{
R Padma, M Sathiya, S Guhanathan* \\ PG \& Research Department of Chemistry, Muthurangam Government Arts College (Autonomous), Vellore, TN, India.
}

Received: December 05, 2016; Accepted: January 25, 2017; Published: March 15, 2017

*Corresponding author: Guhanathan S, PG \& Research Department of Chemistry, Muthurangam Government Arts College (Autonomous), Vellore-632 002, TN, India, E-mail:sai_gugan@yahoo.com

\begin{abstract}
Poly (p-phenylene vinylene) is one of the most important classes of conjugated polymers, with a wide range of applications, such as lightemitting diodes, optoelectronic devices etc. Electroluminescence from OLEDs arises from the radioactive decay of excitation generated by the recombination of electrons and holes injection from two opposite electrodes into the emissive polymer layer. Quinoxaline is a useful n-type building block with high electron affinity and good thermal stability. It has been successfully incorporating small molecules to find utility as electron transport materials in multilayer OLEDs based on PPV. Hence, vinyl benzaldehyde containing quinoxaline derivatives was synthesized using 6-methyl-2, 3-diphenylquinoxaline with terephthaldicarboxaldehyde via Wittig reaction. The structures of synthesised compounds were confirmed by FT-IR, ${ }^{1} \mathrm{H},{ }^{13} \mathrm{C},{ }^{31} \mathrm{P}-\mathrm{NMR}$, and MASS spectral data. The result of photoluminescence studies showed that vinyl benzaldehyde capped quinoxaline exhibited green emission maxima at shorter wavelengths of $454 \mathrm{~nm}$.
\end{abstract}

Keywords: Quinoxaline Derivatives; Photoluminescence; Spectral Studies; Wittig Reaction

\section{Introduction}

A polymer that can be used as light-emission material must have two basic characteristics: electrical conductivity (semi conductive polymer) and high Photoluminescence (PL) efficiency. Electroluminescence (EL), an electrically driven radioactive emission process, is a phenomenon that exists in a wide range of conventional semiconductors, and organic EL was first reported and extensively studied during 1960s [1,2]. Electroluminescence (EL) from OLEDs arises from the radioactive decay of excitations generated by the recombination of electrons and holes injected from two opposite electrodes into the emissive polymeric layer. Balanced rates of injection and transport of both electrons and holes are essential to achieving high External Quantum Efficiency (EQE) in an OLED. However, most emissive conjugated polymers such as PPVs have much higher hole mobility than electron mobility and low electron affinities, causing an imbalance in charge injection and transport results in poor EQEs from singlelayer OLEDs.[3-9] Quinoxaline is a useful n-type building block with high electron affinity and good thermal stability. It has been successfully incorporated in small molecules and polymers for use as electron-transport materials in multilayer OLEDs based on PPV.[10-13] Furthermore, quinoxaline possess an excellent $\pi$-deficient aromatic heterocycle, capable as electron withdrawing portion in push-pull structures for Intermolecular Charge Transfer (ICT) such important ICT along the backbone of the molecule can induce luminescence properties.[14]

In this work, we describe the preparation of new electronaccepting $\pi$-conjugated 2, 3-disubstituted quinoxaline capped vinyl benzaldehyde compound via Wittig reaction in hope of combining both excellent electron-affinitive and light-emitting properties into the compound.

\section{Results and discussion}

The Vinyl Benzaldehyde capped quinoxaline derivatives (VBQUI) have been prepared in four stages similar to our earlier report. [15-17] initially, 6-methyl-2, 3-diphenylquinoxaline was synthesized from benzil and 4-methyl-o-phenylenediamine. For the conversion of methyl to bromomethyl, NBS has been used as a brominating agent via free radical mechanism. Based on Wittig reaction, bromomethyl group is converted to phosphonium salt. The target moiety (VB-QUI) was achieved while reacting phosphonium salt with terephthaldehyde. The formations of various compounds were characterized by UV, FT-IR, ${ }^{1} \mathrm{H},{ }^{31} \mathrm{P}$ NMR. The optical properties including absorption and luminescence of VB-QUI were measured with UV-Vis and Photoluminescence spectral studies.

The UV spectral details of 6-methyl-2, 3-diphenylquinoxaline have been listed as follows, the $n-\pi^{*}$ and $\pi-\pi^{*}$ transitions were observed at $-347.50 \mathrm{~nm}$ and $248.50 \mathrm{~nm}$ implies the $\mathrm{C}=\mathrm{N}$, and $\mathrm{C}=\mathrm{C}$ in the 6-methyl-2, 3-diphenylquinoxaline moiety. The MASS spectrum of 6-methyl-2, 3-diphenylquinoxaline notified that the observed molecular ion peak at 297.21 suits well with the theoretical value.

FTIR spectra of bromomethylated quinoxaline derivative justify the peak at 686.66 for $\mathrm{C}$-Br functional group. ${ }^{1} \mathrm{H}-\mathrm{NMR}$ the 
signal at $4.7 \delta$ confirmed the bromomethylation occurred in the methyl group of quinoxaline derivatives.

${ }^{1} \mathrm{H}$ NMR spectra of phosphonium ylide compound justifies the signal shifted from $4.7 \delta$ to $2.7 \delta$ (ppm). The aromatic ring protons signal was appeared at 7.2-7.9 . The signals at $25.60 \delta$ have been noticed in ${ }^{31} \mathrm{P}$ NMR for the presence of phosphorous in the ylide compound.

Similarly, FTIR spectra of VB-QUI the carbonyl (aldehyde) stretching band have identified near $1689.09 \mathrm{~cm}^{-1} .{ }^{1} \mathrm{H}$ NMR spectra of VB-QUI shows that 7.2-7.9 $\delta$ and 8.1- $9.9 \delta$ for quinoxaline ring protons and phenylene proton respectively. The vinylene proton and aldehyde proton have appeared at $6.9 \delta$, and $10.0 \delta$. The $\lambda_{\max }$ was observed from UV spectrum at $250 \mathrm{~nm}$ indicated $\pi-\pi^{*}$ transition and $348 \mathrm{~nm}$ suggested for $n-\pi^{*}$ transition in VB-QUI. The MASS spectrum of 2, 3-diphenylquinoxalin-6vinyl benzaldehyde clearly pointed out that the molecular ion peak identical to the theoretical value of 413.2.

\section{Photo luminescent properties}

The uv-vis absorption and Photoluminescence spectra of the VB-QUI compound in the ethanol solution have been taken to know about the luminescence behavior of VB-QUI. The uv-vis absorption spectra of the solution exhibited the band around $200-250 \mathrm{~nm}$ may be due to the $\pi-\pi^{*}$ electronic transition associated with the $\pi$-conjugation in the compound. In the PL spectra excitation at $348 \mathrm{~nm}$ exhibits a bluish-green emission approximately around $454 \mathrm{~nm}$.

\section{Conclusions}

The vinyl benzaldehyde capped quinoxaline derivative was synthesised through Wittig reaction using Phosphonium salt and terephthaldehyde. The resulting compound was characterised by FTIR, ${ }^{1} \mathrm{H},{ }^{13} \mathrm{C},{ }^{31} \mathrm{P}$ NMR. Photo luminescent property of the synthesized vinyl benzaldehyde capped quinoxaline derivative was investigated using UV-Vis and fluorescent spectrometer. The VB-QUI compound found to have the photoluminescence with bluish-green emission at $454 \mathrm{~nm}$.

\section{Experimental Materials}

All the chemicals were obtained from Avra chemicals, Hyderabad, India and were used as supplied. Solvents used were purified and dried according to the standard procedure.

\section{Characterization Methods}

The UV-Visible spectra were recorded on an Alpha-Bruker UV spectrophotometer equipped in the range between $200-800 \mathrm{~nm}$. Room temperature FTIR spectra were recorded as $\mathrm{KBr}$ pellet with an Alpha-Bruker FTIR spectrophotometer in the range of 4000$400 \mathrm{~cm}^{-1}$. Nuclear magnetic resonance spectra with different core viz., ${ }^{1} \mathrm{H}$ NMR, ${ }^{13} \mathrm{C}$ NMR and ${ }^{31} \mathrm{P}$ NMR were recorded in either DMSO- $\mathrm{d}_{6}$ or $\mathrm{CDCl}_{3}$ on Bruker ADVANCE III $500 \mathrm{mHz}$ spectrometer.
The fluorescence spectra of the synthesised compound in ethanol were recorded on fluorescence spectrophotometer, FP8500, JASCO. Mass spectroscopy was recorded on ES-FIGIEAN ionization mass spectrometer.

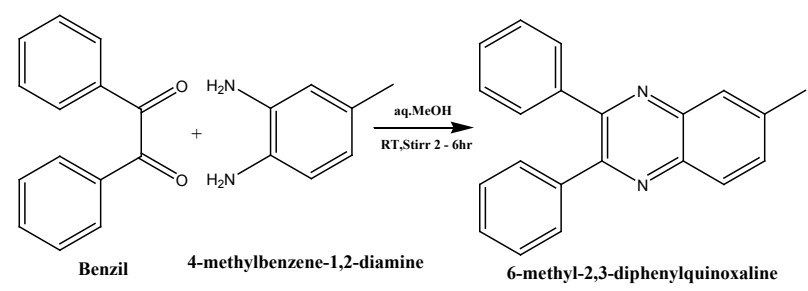

Scheme1: Synthesis of 6-methyl-2, 3-diphenylquinoxaline

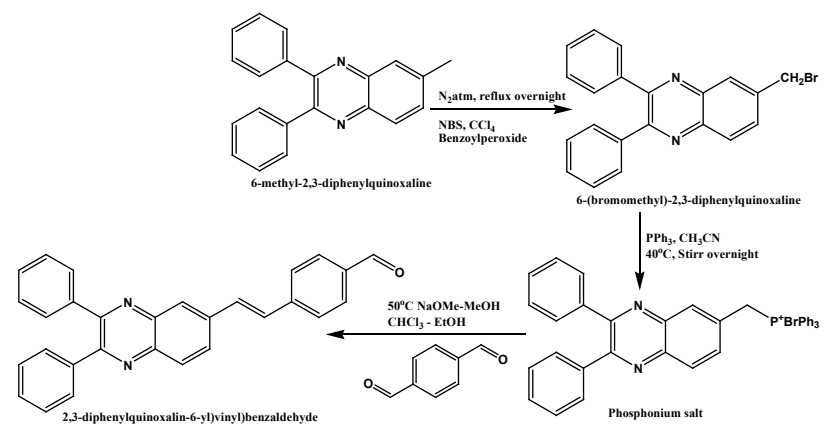

Scheme2: Synthesis of vinyl benzaldehyde capped quinoxaline derivative

\section{Synthesis of 6-methyl-2,3-diphenylquinoxaline}

The $2 \mathrm{mmol}$ of benzil was dissolved in $3 \mathrm{ml}$ of methanol and was made homogeneous by vigorous stirring at room temperature. To this $2 \mathrm{mmol}$ of 4-methylbenzene-1, 2-diamine was added in the form of powder. The progress of the reaction was monitored by TLC. The solvent methanol was evaporated under reduced pressure the solid product thus formed was recrystallized from

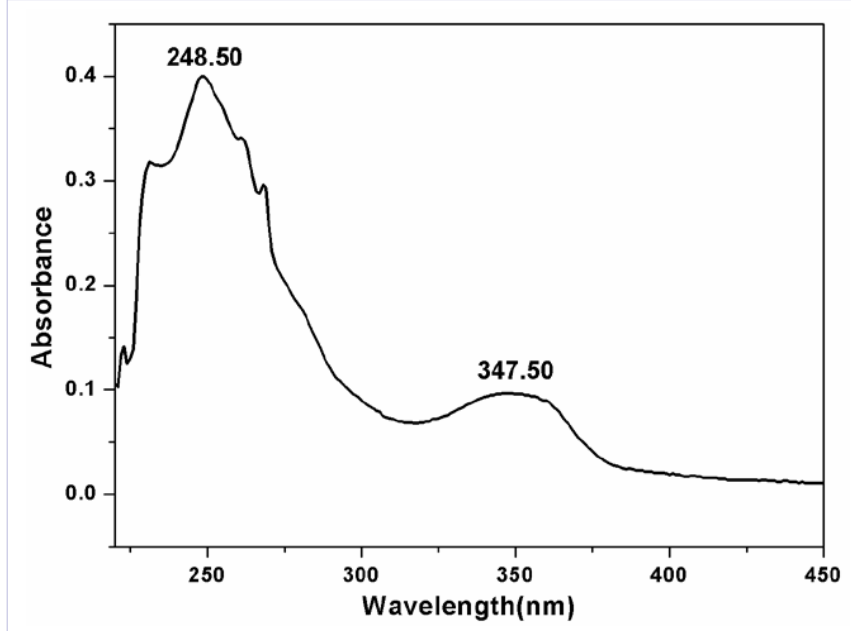

Figure 1: UV spectrum of 6-methyl-2, 3-diphenylquinoxaline. Stage 1: 6-methyl-2, 3-diphenylquinoxaline. 
ethanol. UV ( $\lambda \max , \mathrm{nm}): 248.50,347.50$, FTIR $\left(\mathrm{KBr}, \mathrm{cm}^{-1}\right): 3045.0$ (C-H, st), 1566.5 (C=N, st), 1330.0 (C-N, st) $771.53(\mathrm{C}-\mathrm{H}, \mathrm{b}) .{ }^{1} \mathrm{H}$ NMR $\left(\mathrm{CDCl}_{3}, \mathrm{ppm}\right): 2.6 \delta(3 \mathrm{H}, \mathrm{s}), 7.9 \delta(1 \mathrm{H}, \mathrm{d}) 8.0 \delta(2 \mathrm{H}, \mathrm{s}) 7.5 \delta$ $(4 \mathrm{H}, \mathrm{m}) 7.3 \delta(4 \mathrm{H}, \mathrm{m}) 7.2 \delta(2 \mathrm{H}, \mathrm{m})$ Mass $(\mathrm{m} / \mathrm{z})$ : Calculated M.W 296.38, Observed M.W 297.21( $\left.\mathrm{M}^{+}\right)$.

\section{Synthesis of 6-bromomethyl-2,3-diphenylquinoxaline}

To $0.2964 \mathrm{~g}(0.01 \mathrm{~mol})$ of 6-methyl-2,3-diphenylquinoxaline $0.1780 \mathrm{~g}(0.01 \mathrm{~mol}) \mathrm{N}$-bromosuccinimide in $30 \mathrm{ml}$ of $\mathrm{CCl}_{4}$ containing $0.08 \mathrm{~g}(0.0003 \mathrm{~mol})$ benzoyl peroxide as radical initiator were refluxed overnight. After the completion of reaction, the solid by-product was removed by filtration. Further, the filtrate was washed with $\mathrm{CCl}_{4}$ and the solvent was evaporated to get reddish-yellow solid product. FT-IR $\left(\mathrm{KBr}, \mathrm{cm}^{-1}\right): 2927.94$ (C-H, st), 1616.36 (C=N, st) 1427.32 (C=C, st) 1336.67 (C-N, st) 686.66 (C-Br, st). ${ }^{1} \mathrm{H}-\mathrm{NMR}$ (DMSO, ppm): $4.7 \delta(2 \mathrm{H}, \mathrm{s}) 8.1 \delta$ $(2 \mathrm{H}, \mathrm{m}) 7.8 \delta(1 \mathrm{H}, \mathrm{m}) 7.5 \delta(4 \mathrm{H}, \mathrm{m}) 7.3 \delta(4 \mathrm{H}, \mathrm{m}) 6.8 \delta(2 \mathrm{H}, \mathrm{m})$.

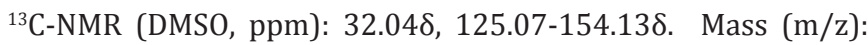
Calculated M.W 375.287, Observed M.W 378.087(M+2).

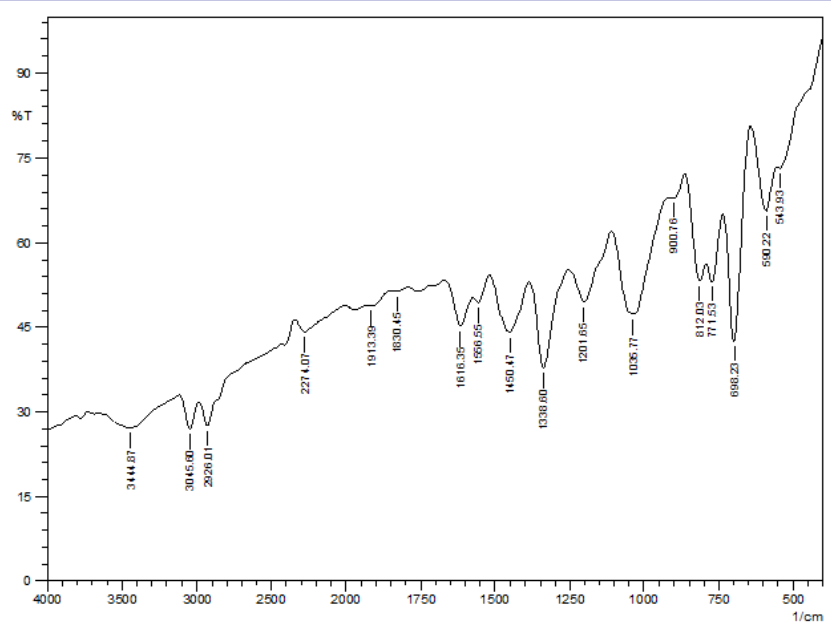

Figure 2: FTIR spectrum of 6-methyl-2, 3-diphenylquinoxaline.

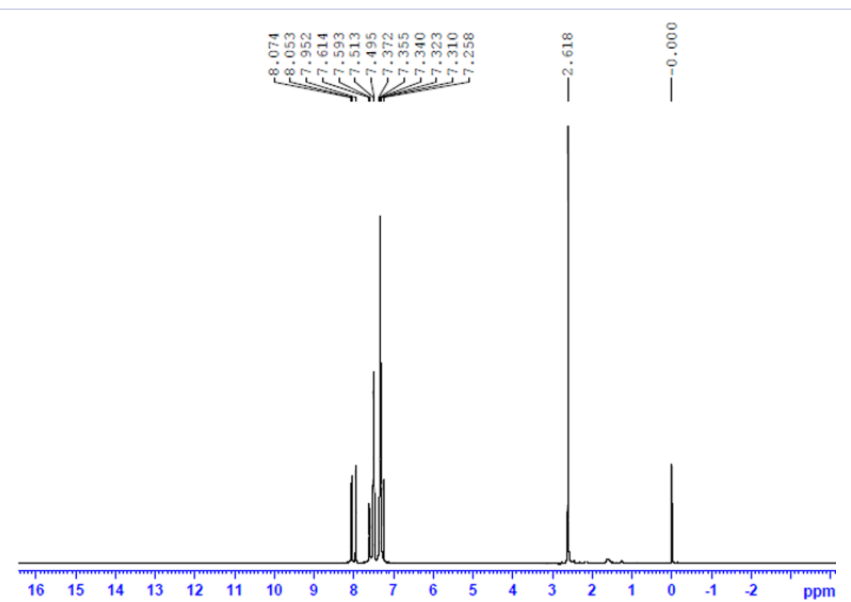

Figure 3: ${ }^{1} \mathrm{H}$ NMR spectrum of 6-methyl-2, 3-diphenylquinoxaline.

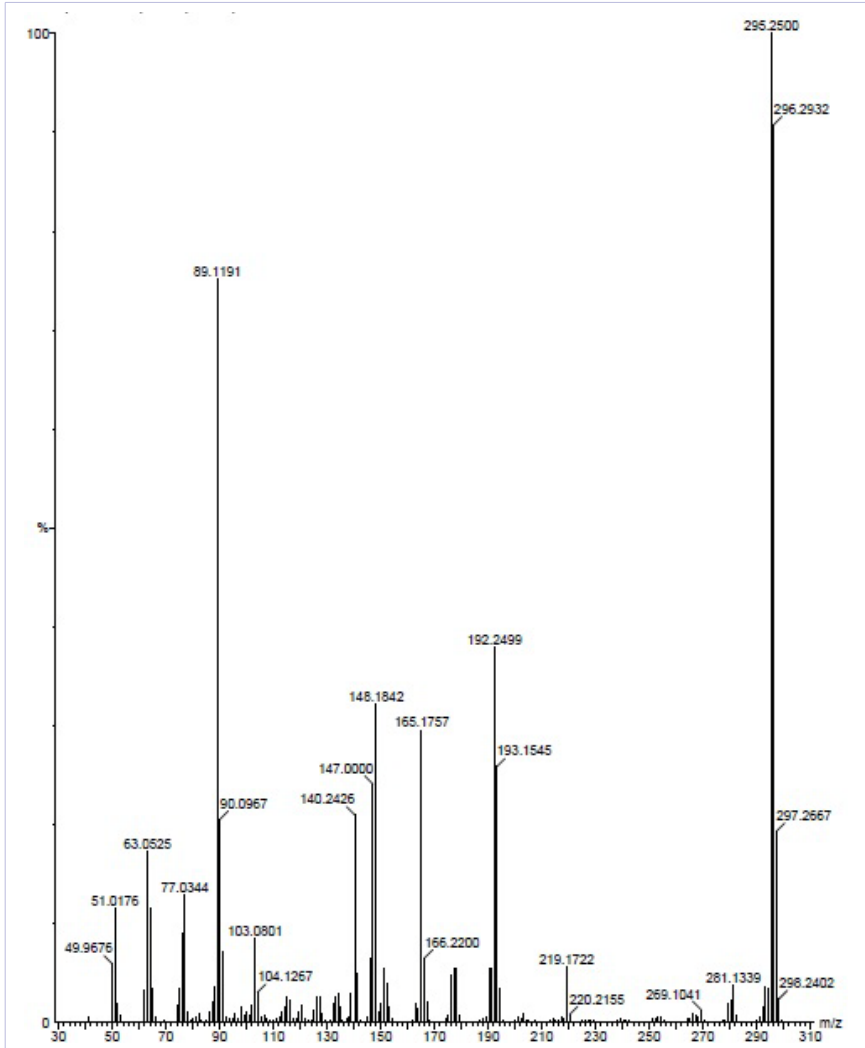

Figure 4: MASS spectrum of 6-methyl-2, 3-diphenylquinoxaline.

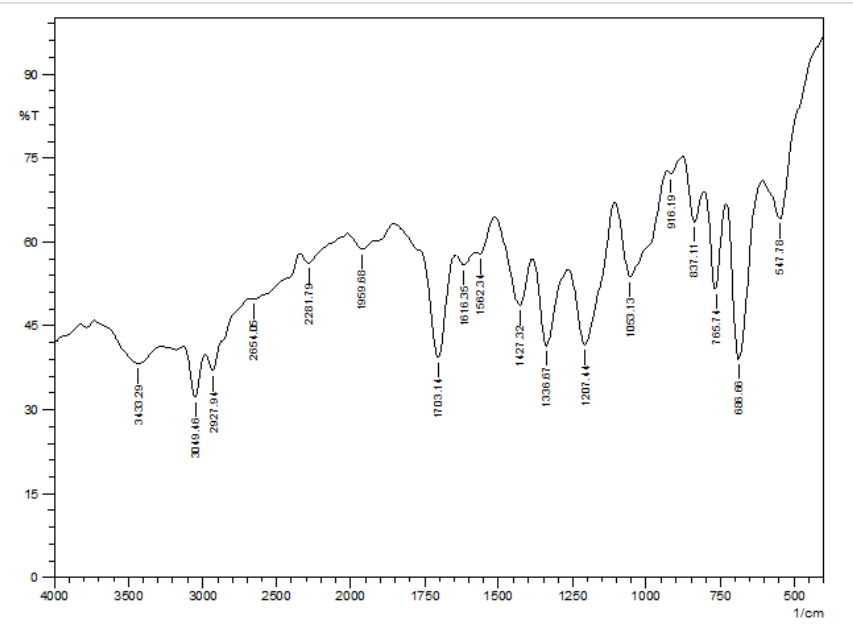

Figure 5: FTIR spectrum of 6-bromomethyl-2, 3-diphenylquinoxaline Stage 2: 6-bromomethyl-2, 3-diphenylquinoxaline

\section{Synthesis of 6-triphenylphosphonium-bromomethyl- 2,3-diphenylquinoxaline}

6-bromomethyl-2, 3-diphenylquinoxaline $(0.38 \mathrm{~g}, 1 \mathrm{mmol})$ and triphenylphosphine $(0.26 \mathrm{~g}, 1 \mathrm{mmol})$ were dissolved together in acetonitrile $(20 \mathrm{ml})$. The solution was stirred overnight at $40^{\circ} \mathrm{C}$. The resulting precipitate was recrystallized from toluenemethanol mixture $(2: 1)$ to yield phosphonium ylide compound. 
${ }^{1} \mathrm{H}-\mathrm{NMR}$ (DMSO, ppm): $2.7 \delta(2 \mathrm{H}, \mathrm{s}), 7.2-7.9 \delta$ aromatic protons. ${ }^{31} \mathrm{P}-\mathrm{NMR}$ (DMSO, ppm): $25.60 \delta(1 \mathrm{P}, \mathrm{s})$.

\section{Synthesis of vinyl benzaldehyde capped quinoxaline derivative}

The phosphonium salt $(0.64 \mathrm{~g}, 1 \mathrm{mmol})$ and terephthaldicarboxaldehyde $(0.135 \mathrm{~g}, 1 \mathrm{mmol})$ were dissolved in a mixture of absolute ethanol and dry chloroform $(12 \mathrm{ml}, 3+1$ $\mathrm{v} / \mathrm{v}$ ) under $\mathrm{N}_{2}$ atmosphere. Further, stoichiometric amount of sodium methoxide ( $25 \mathrm{wt} \%$ in methanol, $1.3 \mathrm{ml}, 5.6 \mathrm{mmol}$ ) was added and the resulting solution was stirred at $50^{\circ} \mathrm{C}$ overnight The product was washed with methanol and reprecipitated from dichloromethane-methanol (1:1) followed by dissolving in acetonitrile - chloroform mixture (1:1) and dried under vacuum to yield $80 \%$ of yellow colour solid product (M.Pt: $110^{\circ} \mathrm{C}$ ) as

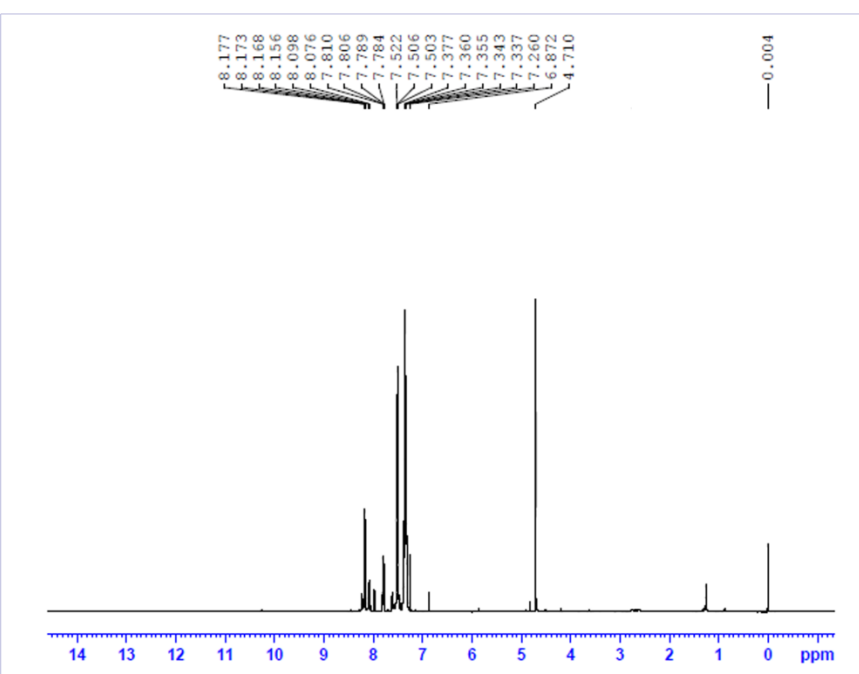

Figure 6: ${ }^{1} \mathrm{H}$ NMR spectrum of 6-bromomethyl-2, 3-diphenylquinoxaline

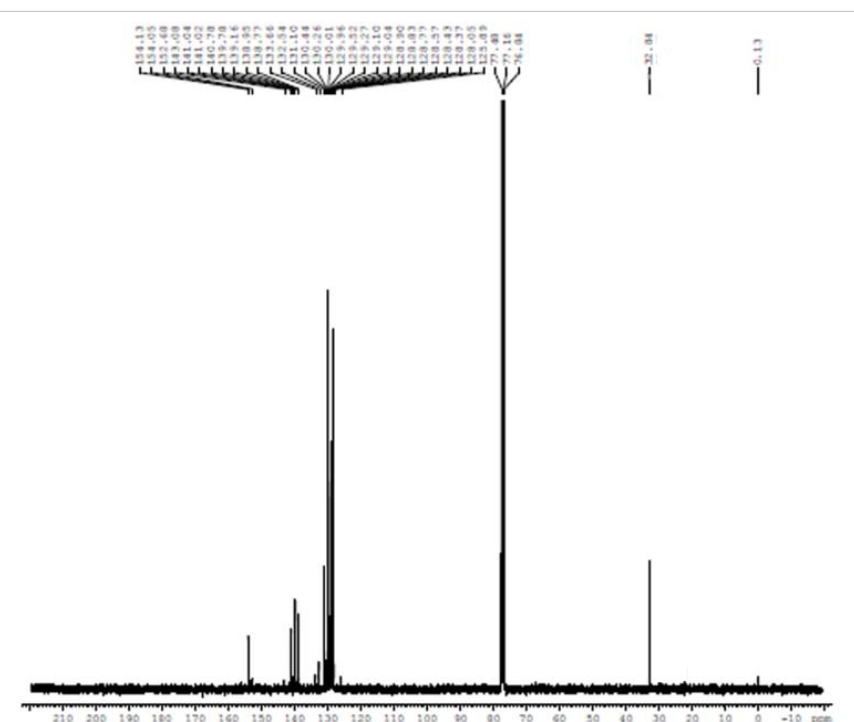

Figure 7: ${ }^{13} \mathrm{C}$ NMR spectrum of 6-bromomethyl-2, 3-diphenylquinoxaline

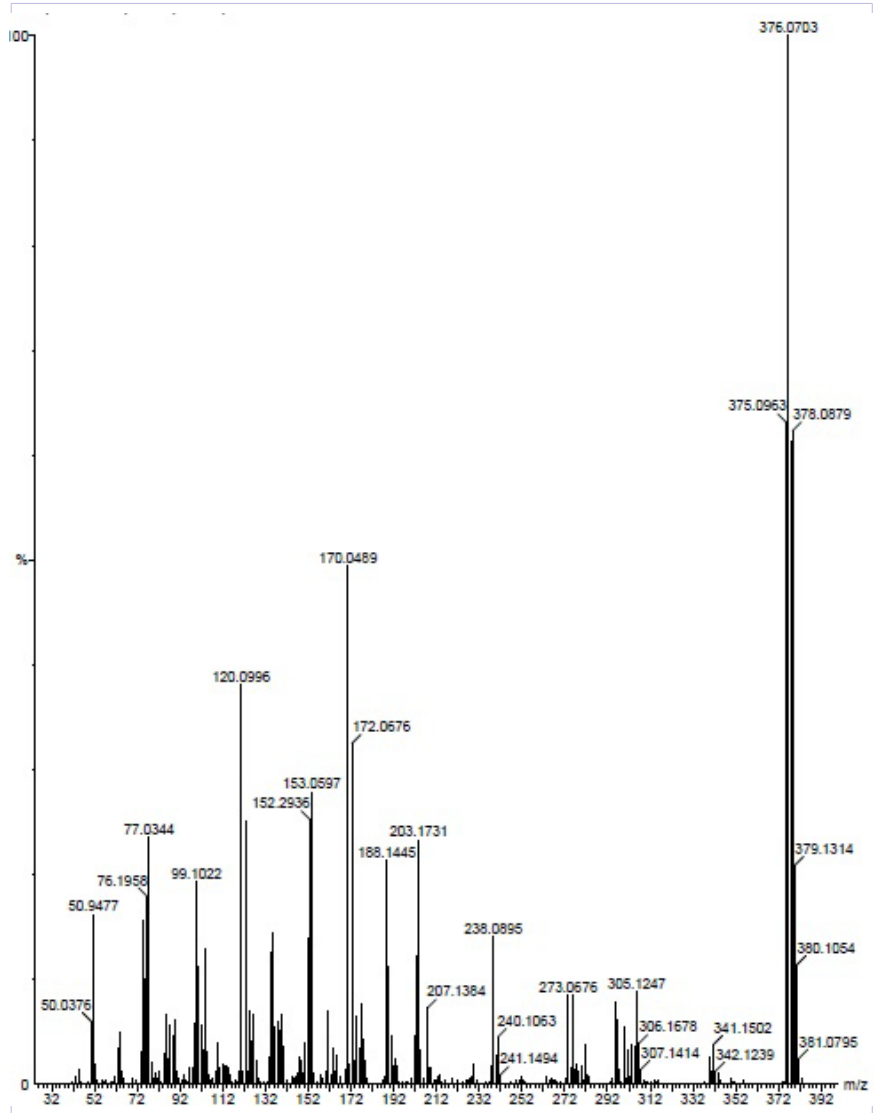

Figure 8: MASS spectrum of 6-bromomethyl-2, 3-diphenylquinoxaline

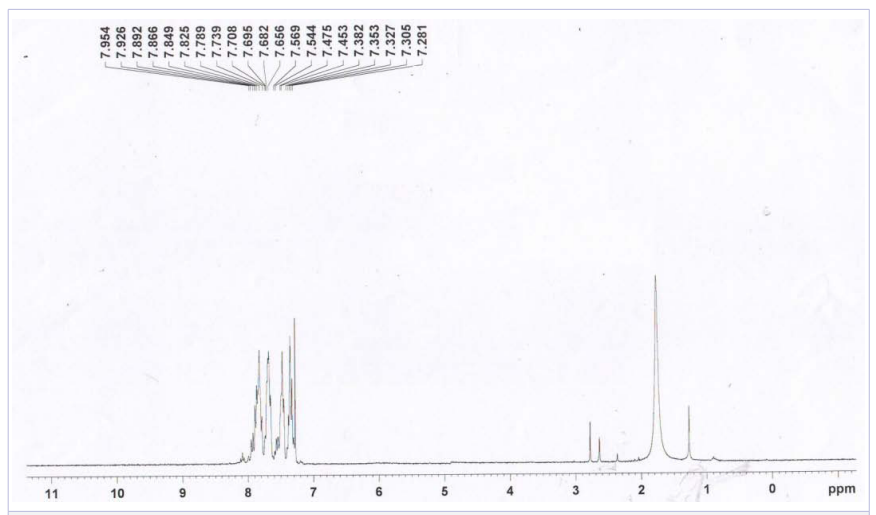

Figure 9: ${ }^{1} \mathrm{H}$ NMR spectrum of 6-triphenylphosphonium-bromomethyl-2, 3-diphenylquinoxaline.

Stage 3: 6-triphenylphosphonium-bromomethyl-2,

3-diphenylquinoxaline

vinyl benzaldehyde capped quinoxaline derivative. $\operatorname{UV}(\lambda \max$, $\mathrm{nm}): 260.03 \mathrm{~nm}\left(\pi-\pi^{*}\right), 348.03 \mathrm{~nm}\left(\mathrm{n}-\pi^{*}\right)$; FT-IR $(\mathrm{KBr}, \mathrm{cm}-1)$ : 2918.34 (C-H, st), 1689.09 (C=O, st), 1 (C=N, st), 1429.01 (C=C), 1347.75 (C-N, st); ${ }^{1} \mathrm{H}-\mathrm{NMR}\left(\mathrm{CDCl}_{3}, \mathrm{ppm}\right): 10.0 \delta(1 \mathrm{H}, \mathrm{s}), 9.9 \delta(2 \mathrm{H}$, m) $8.1 \delta(1 \mathrm{H}, \mathrm{m}) 7.9 \delta(2 \mathrm{H}, \mathrm{m}) 7.7 \delta(2 \mathrm{H}, \mathrm{m}) 7.5 \delta(4 \mathrm{H}, \mathrm{m}) 7.3 \delta(2 \mathrm{H}$, m) $7.2 \delta(2 \mathrm{H}, \mathrm{m}) 6.9 \delta(2 \mathrm{H}, \mathrm{m}) ;{ }^{13} \mathrm{C}-\mathrm{NMR}\left(\mathrm{CDCl}_{3}, \mathrm{ppm}\right): 191.0 \delta$, 127.29-154.10 $\delta$; Mass(m/z): Calculated M.W 412.48, Observed M.W 413.2(M+1); PL : 454nm Emission 


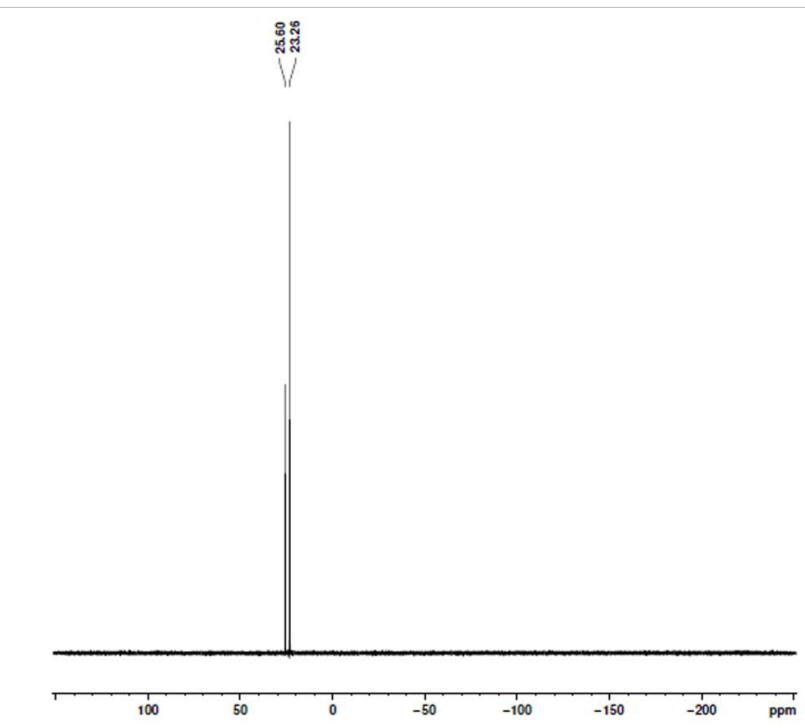

Figure 10: ${ }^{31} \mathrm{P}$ NMR spectrum of 6-triphenylphosphonium-bromomethyl-2, 3-diphenylquinoxaline

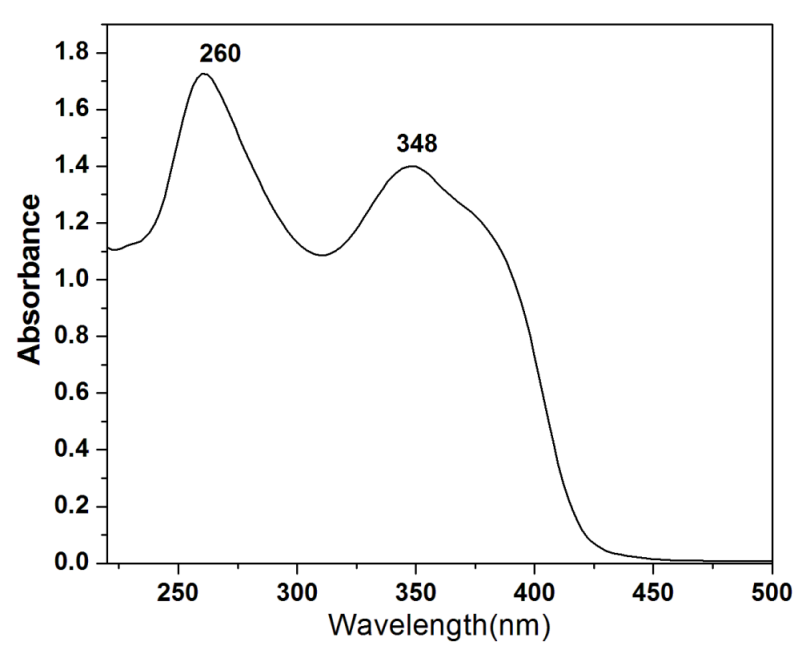

Figure 11: UV spectrum of 2, 3-diphenylquinoxalin-6-vinyl benzaldehyde

Stage 4: 2, 3-diphenylquinoxalin-6-vinyl benzaldehyde

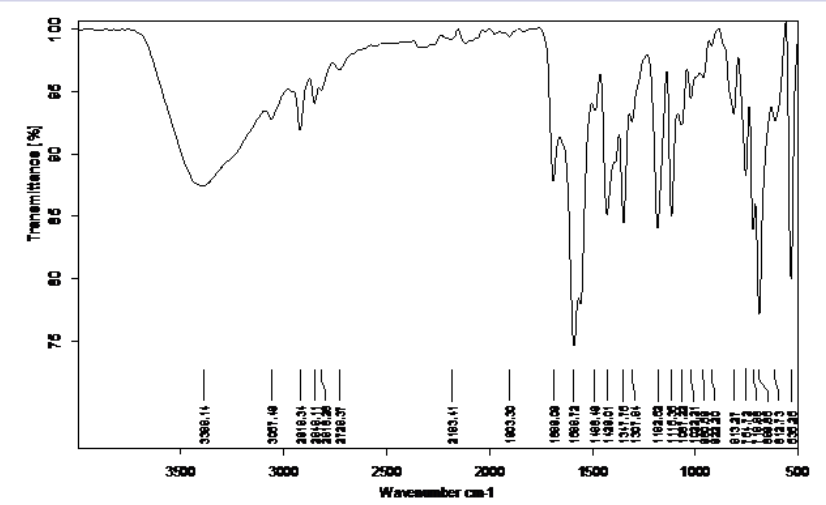

Figure 12: FTIR spectrum of 2, 3-diphenylquinoxalin-6-vinyl benzaldehyde

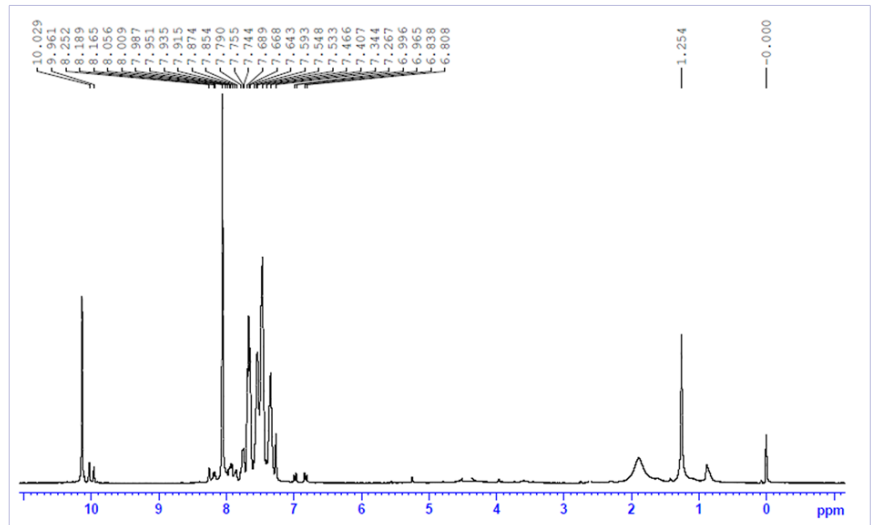

Figure 13: ${ }^{1} \mathrm{H}$ NMR spectrum of 2, 3-diphenylquinoxalin-6-vinyl benzaldehyde

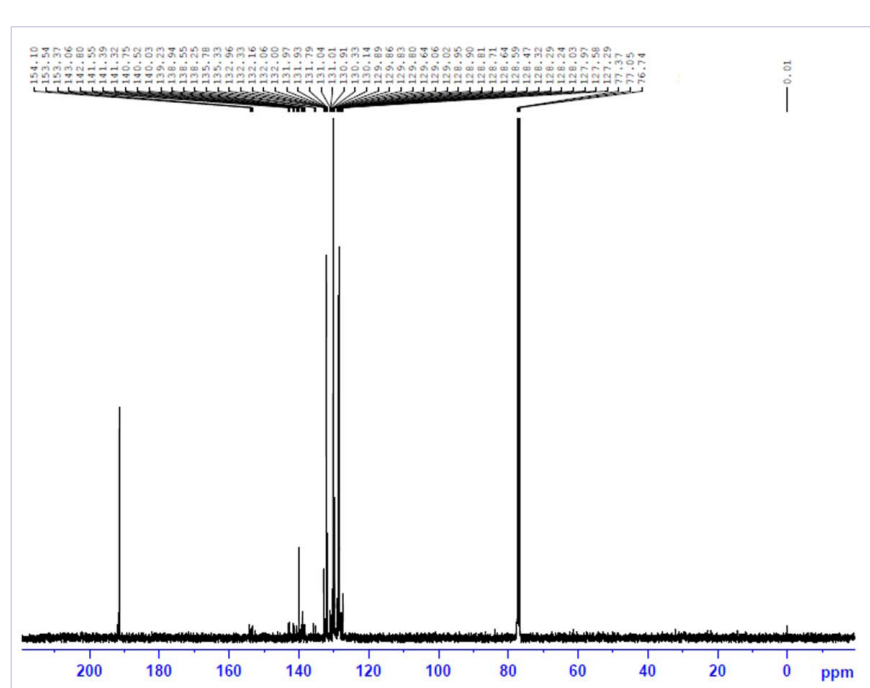

Figure 14: ${ }^{13} \mathrm{C}$ NMR spectrum of 2, 3-diphenylquinoxalin-6-vinyl benzaldehyde

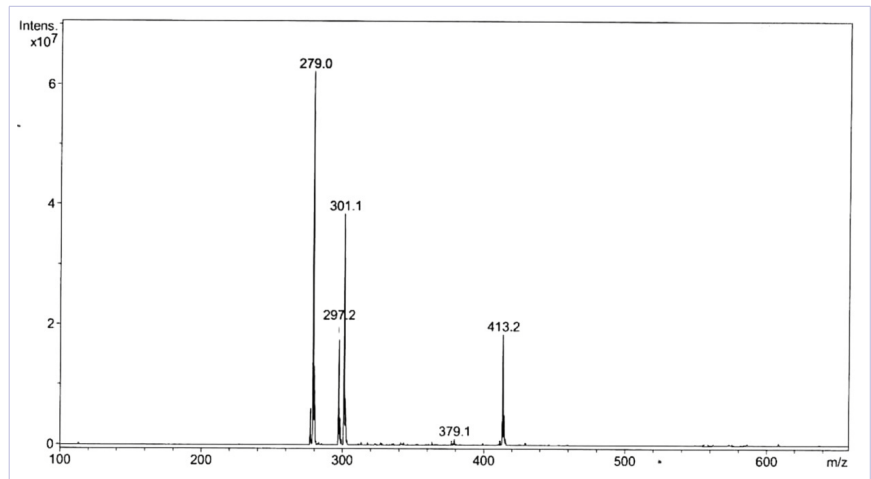

Figure 15: MASS spectrum of 2, 3-diphenylquinoxalin-6-vinyl benzaldehyde

\section{Acknowledgement}

We gratefully acknowledge the Muthurangam Govt Arts College (Autonomous) for providing laboratory facilities. We thank SIF-VIT and SAIF-IIT Madras for recording spectral data. 


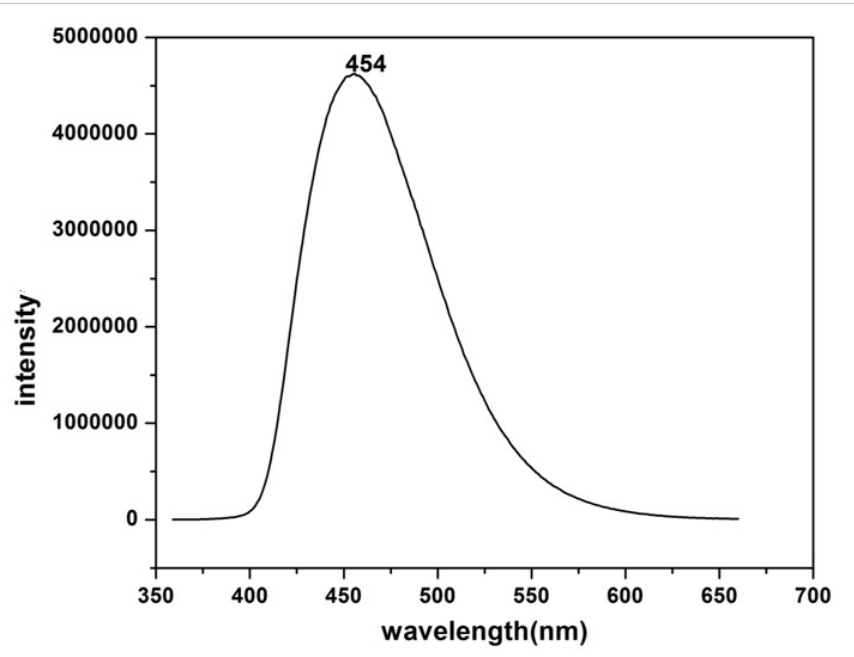

Figure 16: PL spectrum of 2, 3-diphenylquinoxalin-6-vinyl benzaldehyde

\section{References}

1. Pope M, Kallmann H, Magnante P. Electroluminescence in organic crystals. J Chem Phys. 1963;38:2042-2043.

2. Helfrich $\mathrm{W}$, Schneider WG. Recombination radiation in anthracene crystal. Phys. Rev. Lett.1965;14:229-231.

3. (a) Kraft A, Grimsdale AC, Holmes AB. Electroluminescent Conjugated Polymers - Seeing Polymers in a New Light. Angew Chem Int Ed.1998;37

4. 402-428. (b) Friend RH, Gymer RW, Holmes AB, Burroughes JH, Marks $\mathrm{RN}$, Taliani $\mathrm{C}$, et al. Electroluminescence in conjugated polymers Nature (London). 1999;397:121-128. (c) Rees ID, Robinson KL, Holmes AB, Towns CR, O’Dell R. Recent developments in light-emitting polymers. Bull MRS. 2002;27(6):451-455."

5. JH, Marks RN, Taliani C, et al. Electroluminescence in conjugated polymers. Nature (London). 1999;397:121-128. (c) Rees ID, Robinson KL, Holmes AB, Towns CR, O’Dell R. Recent developments in lightemitting polymers. Bull MRS. 2002;27(6):451-455.

6. (a)Rothberg LJ, Lovinger AJJ. Maternm nnnnnnnnnnq Res. 1996;11:3174. (b) Heeger AJ. Light emission from semiconducting polymers: Light-emitting diodes, light-emitting electrochemical cells, lasers and white light for the future. Solid State. 1998;107(11):673. (c) Sheats JR, Antoniadis H, Hueschen M, Leonard W, Miller J, Moon R, et al. Organic Electroluminescent Devices. Science. 1996;273(5277):884888.

7. (a)Tarkka RM, Zhang X, Jenekhe SA. Electrically Generated Intramolecular Proton Transfer: Electroluminescenceand Stimulated Emission from Polymers. J Am Chem Soc. 1996;118(39):94389439. (b) Zhang X, Shetty AS, Jenekhe SA. Electroluminesence and Photophysical Properties of Polyquinolines. Macromolecules. 1999;32(22):7422-7429. DOI: 10.1021/ma990960+

8. (a)Jenekhe SA, Zhang X,Chen XL, Choong VE, Gao Y, Hsieh BR. Finite Size Effects on Electroluminescence of Nanoscale Semiconducting Polymer Heterojunctions. Chem Mater. 1997;9(2):409-412. (b) Zhang X, Jenekhe SA. Electroluminescence of Multicomponent Conjugated Polymers. 1. Roles of Polymer/Polymer Interfaces in Emission Enhancement and Voltage-Tunable Multicolor Emission in Semiconducting Polymer/Polymer Heterojunctions. Macromolecules. 2000;33(6):2069. DOI: 10.1021/ma991913k (c)Tonzola Cj, Alam MM, Jenekhe SA. New Soluble n-Type Conjugated Copolymer for Light

\section{Emitting Diodes. Adv Mater. 2002;14(15):1086-1090.}

9. (a)Gustafsson G, Cao Y, Treacy GM, Klavetter F, Colaneri N, Heeger AJ Flexible light-emitting diodes made from soluble conducting polymers. Nature (London). 1992;357:477-479. (b) Greenham NC, Moratti SC, Bradley DDC, Friend RH, Holmes AB. Efficient light emitting diodes based on polymers with high electron affinities. Nature (London). 1993;365:628-630. doi:10.1038/365628a0

10. (a) Zhu Y, Alam MM, Jenekhe SA. Regioregular Poly(4-alkylquinoline) s: Synthesis, Self-Organization, and Properties. Macromolecules. 2002;35(26):9844-9846. (b) ZhuY,Alam MM, Jenekhe SA. Regioregular head to tail poly(4-alkylquinoline)s: synthesis, characterisation, selforganization, photophysics, and electroluminescence of new n-type conjugated polymers. Macro molecules. 2003;36(24):8958-8968. DOI: $10.1021 / \mathrm{ma} 0348021$

11. (a) Tonzola CJ, Alam MM, Kaminsky W, Jenekhe SA. New n-Type Organic Semiconductors: Synthesis, Single Crystal Structures, Cyclic Voltammetry, Photophysics, Electron Transport, and Electroluminescence of a Series of Diphenylanthrazolines. J Am Chem Soc. 2003;125(44):13548-13558. (b) Alam MM, Jenekhe SA. Polybenzobisazoles Are Efficient Electron Transport Materials for Improving the performance and Stability of Polymer Light-Emitting Diodes. Chem Mater. 2002;14(11):4775. DOI: 10.1021/cm020600s

12. (a) Kanbara T, Yamamoto T, Preparation and properties of new .pi. -conjugated poly(quinoxaline-5,8-diyl) and poly(2,3diethylquinoxaline-5,8-diyl). Enhancement of electron-accepting properties of poly(arylenes) by introduction of imine nitrogen. Macromolecules. 1993;26:3464.(b) Kushida T, Inoue T, Kanbara T. Preparation of New Electron-Accepting $\pi$-Conjugated Polyquinoxalines. Chemical and Electrochemical Reduction, Electrically Conducting Properties, and Use in Light-Emitting Diodes. J Am Chem Soc. 1996;118(16):3930. DOI: 10.1021/ja954173d

13. Jandke M, Strohriegl P, Berleb S, Werner E, Bru“ tting W. Phenylquinoxaline Polymers and Low Molar Mass Glasses as Electron-Transport Materials in Organic Light-Emitting Diodes. Macromolecules. 1998;31(19):6434-6443.

14. Schmitz C, Po"sch P, Thelakkat M, Schmidt HW, Montali A, Feldman $\mathrm{K}$, et al. Polymeric Light-Emitting Diodes Based on Poly(p-phenylene ethynylene), Poly(triphenyldiamine), and Spiroquinoxaline. Adv Funct Mater. 2001;11(1):41-46

15. (a) Fukuda T, Kanbara T, Yamamoto T, Ishikawa K, Takezoe H, Fukuda A. Polyquinoxaline as an excellent electron injecting material for electroluminescent device. Appl. Phys. Lett, 1996;68(17):2346. (b) O’Brien D, Weaver MS, Lidzey DG, Bradley DDC. Use of poly(phenyl quinoxaline) as an electron transport material in polymer light-emitting diodes. Appl Phys Lett. 1998;69:881. doi: 10.1063/1.117975 (c) Cui Y, Zhang X, Jenekhe SA. Thiophene-Linked Polyphenylquinoxaline: A New Electron Transport Conjugated Polymer for Electroluminescent Devices. Macromolecules. 1999;32(11): 3824-3826. DOI: 10.1021/ ma9901994

16. Sylvain Achelle, Chris-ineBaudequin, Nelly Ple. Luminescent materials incorporating pyrazine or quinoxaline moiestie. Dyes and Pigments. Elsevier. 2013;98(3):575-600. DOI: 10.1016/j.dyepig.2013.03.030

17. Karpagam S, Guhanathan S. Emitting oligomer containing quinoline group; synthesis and photophysical properties of conjugated oligomer obtained by Wittig reaction. Journal of Luminescences. 2014;145:752759.

18. Karpagam S, Guhanathan S, Sakthivel P. Applications of Wittig reactions in Dibenzo18-Crown-6-Ether substituted Phenylene Vinylene Oligomer - Synthesis, Photoluminescent and Dielectric properties. Journal of Applied Polymer Science. 2011;120(2):960967. 